\title{
ANALYSIS OF MULTIPLE BIRTHS IN JAPAN IV. BODY WEIGHT OF 4,317 TWIN PAIRS AT ONE YEAR OF AGE
}

\author{
Akio Asaka, ${ }^{1}$ Yoko Imaizumi, ${ }^{2}$ and Eiji InOUYe ${ }^{1}$ \\ ${ }^{1}$ Institute of Brain Research, University of Tokyo School of Medicine, \\ Tokyo, Japan \\ ${ }^{2}$ Institute of Population Problems, Ministry of Health and Welfare, \\ Tokyo, Japan
}

\begin{abstract}
Summary Body weight of twins at one year of age was analysed in comparison with that at birth. Mean weight at one year of age was the heaviest in the first-born males followed by the second-born males, the first-born females and the second-born females in this order, the same as that at birth of twin individuals, who were live-born and surviving at one year of age. As for the distribution of weight at one year of age, lower coefficient of variation, larger kurtosis and positively changed skewness were demonstrated, if compared to that at birth of "the live birth and surviving at one year of age" twin individuals. Increased intraclass correlation coefficient and decreased percent deviation of weight within the pair were observed from birth to the age of one year. The features were more clearly seen in MZ twins. A close relationship between the weight at bith and that at one year of age was seen, as for twin individuals and twin pairs combined. Growth rate of the sum of weight of twins at one year of age was linearly decreased as the sum of weight at birth was increased.
\end{abstract}

\section{INTRODUCTION}

This study deals with body weight of twins at one year of age in relation to survival states at birth, sex compositions, birth order within pairs and zygosity.

\section{SUBJECTS AND METHODS}

Source of data is similar to those of the previous series (Imaizumi and Inouye, 1979; Imaizumi, Asaka and Inouye, 1979): "Survey B" of "Socio-economic Aspects of Vital Events--Plural Births in 1975" (Health and Welfare Statistics and Information Department, Ministry of Health and Welfare), which includes data on 4,361 
Table 1. Survival states at birth and at one year of age of 4,317 pairs of twins according to sex compositions.

\begin{tabular}{|c|c|c|c|c|c|c|c|}
\hline \multirow{2}{*}{ At birth } & \multirow{2}{*}{ At one year of age } & \multicolumn{6}{|c|}{ Sex compositions } \\
\hline & & MM & $\mathrm{MF}$ & FM & FF & $U^{*}$ & Total \\
\hline \multirow[t]{4}{*}{ Live-Live } & Surviving-Surviving & 1,421 & 344 & 297 & 1,417 & 3 & 3,482 \\
\hline & Surviving-Dead & 66 & 10 & 16 & 41 & 1 & 134 \\
\hline & Dead-Surviving & 46 & 4 & 4 & 21 & 0 & 75 \\
\hline & Dead-Dead & 27 & 10 & 3 & 22 & 0 & 62 \\
\hline \multirow[t]{2}{*}{ Live-Still } & Surviving- & 52 & 12 & 12 & 65 & 8 & 149 \\
\hline & Dead- & 8 & 1 & 0 & 5 & 1 & 15 \\
\hline \multirow[t]{2}{*}{ Still-Live } & -Surviving & 20 & 7 & 4 & 15 & 4 & 50 \\
\hline & -Dead & 7 & 3 & 0 & 4 & 2 & 16 \\
\hline Still-Still & & 136 & 40 & 18 & 113 & 27 & 334 \\
\hline Total & & 1,783 & 431 & 354 & 1,703 & 46 & 4,317 \\
\hline
\end{tabular}

* Sex of one or both twins is unknown.

sets of Japanese multiple births in the first half of 1974. Among the multiple births the number of twin pairs is 4,317. Items included in "Survey B" are body weight at birth and at one year of age, maternal age, gestational age, health condition of the mother and children, method of nutritions and other items. The subjects of "Survey B" constitute a part of those of "Survey A" (see Asaka, Imaizumi and Inouye, 1980). Survival states at birth and at one year of age are shown in Table 1 according to sex compositions.

\section{RESULTS}

As is shown in Table 2, mean body weight at birth was the heaviest in twin individuals with live birth and surviving at one year of age, followed by those with live birth and not surviving at one year of age, by those with stillbirth in this order, irrespective of the sex and birth order. Mean body weight at one year of age was the heaviest in the first-born males, followed by the second-born males, the firstborn females and the second-born females in this order, which indicated the same order at birth. In this sample the coefficients of variation at one year of age are 11.66 (first-born males), 12.04 (second-born males), 12.40 (first-born females), and 12.54 (second-born females), which were reduced to around half of those at birth, $18.26,18.55,18.66$, and 18.93, respectively. Kurtosis was larger at one year of age than at birth, and skewness was changed from negative at birth to positive at one year of age. 


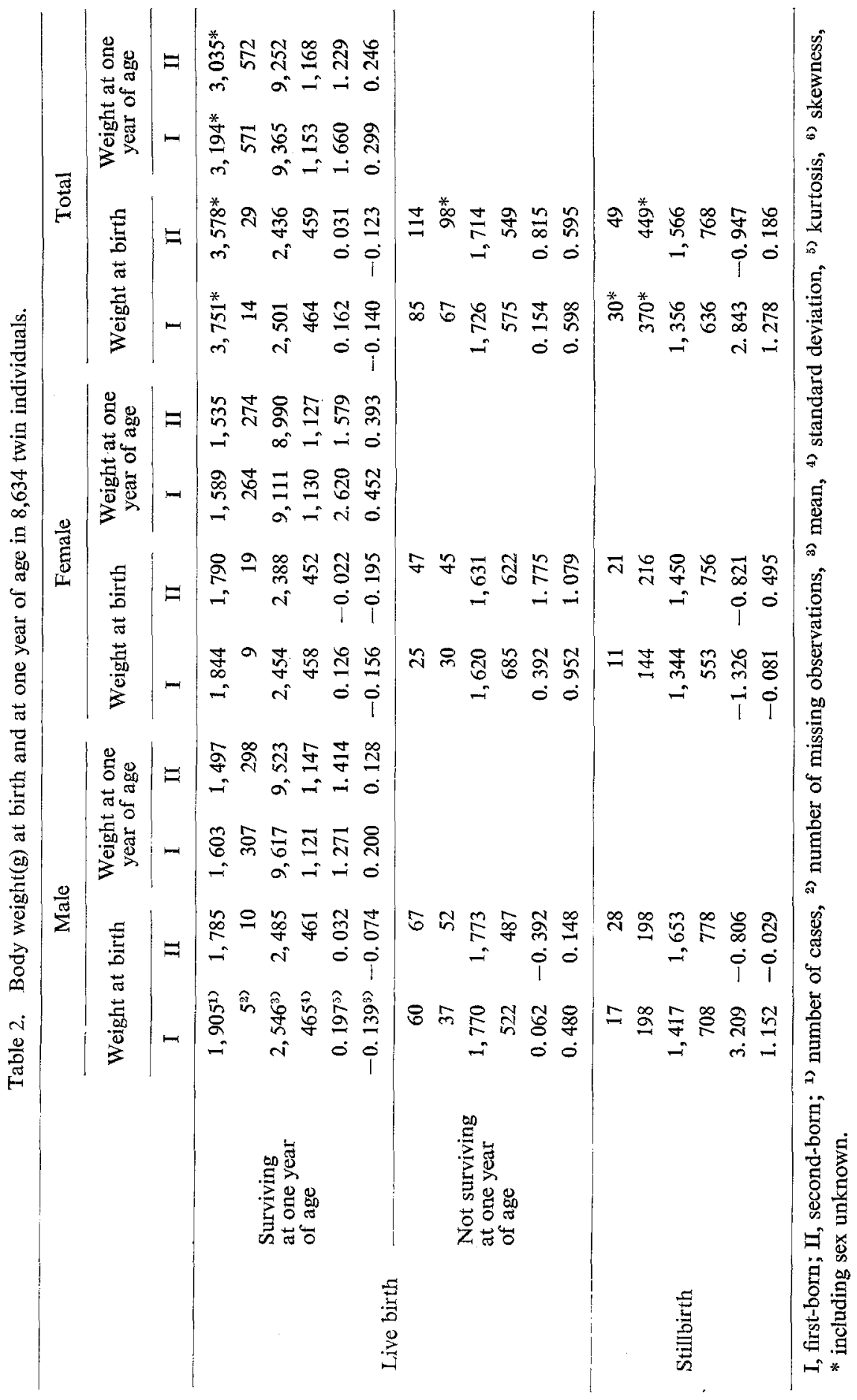


Among twin individuals with live birth but not surviving at one year of age, age at death was recorded in 135 first-born and 188 second-born individuals, of which body weight at birth was available in 77 twin individuals in the former and 103 in the latter (Table 3). Age at death was divided into three groups, as is shown in Table 3, and body weight at birth was subjected to analysis of variance. The result is shown in Table 3 , and significant differences were seen among three groups. Mean body weight at birth was the lightest in twin individuals died at age one month or less, intermediate in those from one to three months and the heaviest in those four months or more, in both the first-born and the second-born twin individuals.

Table 3. Weight at birth of twin individuals with live birth and not surviving at one year of age according to age at death.

\begin{tabular}{lllll}
\hline & \multicolumn{1}{c}{ Age at death } & Number & Mean & $\begin{array}{c}\text { Standard } \\
\text { deviation }\end{array}$ \\
\hline \multirow{2}{*}{ First-born } & One month or less & $52(98)^{*}$ & 1,492 & 406 \\
& One to three months & $14(20)$ & 1,971 & 593 \\
& Four months or more & $11(17)$ & 2,488 & 448 \\
\hline \multirow{2}{*}{ Second-born } & Total & $77(135)$ & 1,721 & 574 \\
& One month or less & $77(150)$ & 1,611 & 490 \\
& One to three months & $14(23)$ & 2,068 & 384 \\
& Four months or more & $12(15)$ & 2,185 & 694 \\
\hline & Total & $103(188)$ & 1,740 & 548 \\
\hline
\end{tabular}

Table of analysis of variance

\begin{tabular}{llrrr}
\hline & & Sum of square & Degree of freedon & Mean square \\
\hline First-born & Between groups & $10,085,184.13$ & 2 & $5,042,592.06$ \\
& Within groups & $14,997,533.38$ & 74 & $202,669.37$ \\
& Total & $25,082,717.51$ & 76 & \\
\cline { 2 - 5 } & F $=24.88$ & & 2 & $2,584,154.88$ \\
\hline \multirow{2}{*}{ Second-born } & Between groups & $5,168,309.75$ & 100 & $254,739.88$ \\
& Within groups & $25,473,988.50$ & 102 & \\
& Total & $30,642,298.25$ & & \\
& F $=10.14$ & & & \\
\end{tabular}

* Figures in parentheses indicate total number of twin individuals including unknown body weight at birth. 
In the following chapter analysis was made solely on Live-Live and SurvivingSurviving 3,482 pairs (Table 1). After excluding pairs with unknown sex and/or body weight in one or both twins, intraclass correlation ocefficient of body weight at birth and at one year of age was computed according to sex compositions (Table 4). Correlation coefficient was higher in like-sexed than in unlike-sexed twins at birth as well as at one year of age. Increased correlation coefficients at one year of age were seen, except for FM sex composition, if compared to those at birth.

Table 5 shows mean percent deviation of body weight within the pair at birth and at one year of age according to sex compositions. Percent deviation was defined as the percentage of the absolute difference divided by the sum of twins. As seen in Table 5, the figure was larger at birth than at one year of age in each sex composition and in total twins. At one year of age the figure was lower in likesexed than in unlike-sexed pairs. The median of the percent deviation was 4.940 at birth and 2.326 at one year of age, and the pairs were classified into two groups, below or above the median (Table 6). Using Weinberg's method, numbers of MZ and $\mathrm{DZ}$ twins were estimated at birth and at one year of age, separately for the two groups, below and above the median of the percent deviation. As zygosity of the same-sexed pairs was not identified in the present sample, the estimated number of $\mathrm{MZ}$ or $\mathrm{DZ}$ was obtained on the assumption that the condition was equal between the same-sexed and the opposite-sexed DZ. At birth the relative frequency

Table 4. Intraclass correlation coefficient of body weight at birth and at one year of age according to sex compositions.

\begin{tabular}{clll}
\hline Sex compositions & \multicolumn{1}{c}{ At birth } & \multicolumn{1}{c}{ At one year of age } \\
\hline MM & 0.6483 & $(\mathrm{n}=1,415)$ & $0.8035 \quad(\mathrm{n}=1,179)$ \\
MF & 0.4432 & $(\mathrm{n}=338)$ & $0.5121 \quad(\mathrm{n}=285)$ \\
FM & $0.5883 \quad(\mathrm{n}=290)$ & $0.5038 \quad(\mathrm{n}=244)$ \\
FF & $0.6299 \quad(\mathrm{n}=1,399)$ & $0.7857 \quad(\mathrm{n}=1,204)$ \\
\hline Total & $0.6234 \quad(\mathrm{n}=3,422)$ & $0.7496 \quad(\mathrm{n}=2,912)$ \\
\hline
\end{tabular}

Table 5. Mean percent deviation of body weight at birth and at one year of age.

\begin{tabular}{clll}
\hline Sex compositions & \multicolumn{2}{c}{ At birth } & At one year of age \\
\hline MM & 6.002 & $(\mathrm{n}=1,415)$ & $2.558 \quad(\mathrm{n}=1,179)$ \\
MF & 7.188 & $(\mathrm{n}=338)$ & $4.883 \quad(\mathrm{n}=285)$ \\
FM & 6.186 & $(\mathrm{n}=290)$ & $4.709 \quad(\mathrm{n}=244)$ \\
FF & $6.265 \quad(\mathrm{n}=1,399)$ & $2.704 \quad(\mathrm{n}=1,204)$ \\
\hline Total & $6.241 \quad(\mathrm{n}=3,442)$ & $3.026 \quad(\mathrm{n}=2,912)$ \\
\hline
\end{tabular}


Table 6. Number of pairs according to percent deviation of weight at birth and at one year of age, below or above the median (4.940 or 2.326).

\begin{tabular}{|c|c|c|c|c|c|c|}
\hline \multirow[b]{2}{*}{$\begin{array}{l}\text { Sex com- } \\
\text { position }\end{array}$} & \multicolumn{3}{|c|}{ At birth } & \multicolumn{3}{|c|}{ At one year of age } \\
\hline & $\begin{array}{l}\text { Percent devia- } \\
\text { tion less than } \\
\text { or equal to } \\
4.940\end{array}$ & $\begin{array}{c}\text { Percent devia- } \\
\text { tion more than } \\
4.940\end{array}$ & Total & $\begin{array}{l}\text { Percent devia- } \\
\text { tion less than } \\
\text { or equal to } \\
\quad 2.326\end{array}$ & $\begin{array}{l}\text { Percent devia- } \\
\text { tion more than } \\
2.326\end{array}$ & Total \\
\hline MM & 729 & 686 & 1,415 & 660 & 519 & 1,179 \\
\hline MF & 145 & 193 & 338 & 87 & 198 & 285 \\
\hline $\mathrm{FM}$ & 139 & 151 & 290 & 62 & 182 & 244 \\
\hline FF & 708 & 691 & 1,399 & 664 & 540 & 1,204 \\
\hline Total & 1,721 & 1,721 & 3,442 & 1,473 & 1,439 & 2,912 \\
\hline \multicolumn{7}{|c|}{ Estimated number } \\
\hline MZ & $1,153(52.7 \%)$ & $1,033(47.3 \%)$ & 2,186 & $1,175(63.4 \%)$ & $679(36.6 \%)$ & 1,854 \\
\hline $\mathrm{DZ}$ & $568(45.2 \%)$ & $688(54.8 \%)$ & 1,256 & $298(28.2 \%)$ & $760(71.8 \%)$ & 1,058 \\
\hline Total & 1,721 & 1,721 & 3,442 & 1,473 & 1,439 & 2,912 \\
\hline
\end{tabular}

Table 7. Interclass correlation coefficient between the weight at birth and at one year of age.

\begin{tabular}{cclllll}
\hline Sex compositions & \multicolumn{2}{c}{ First-born } & \multicolumn{2}{c}{ Second-born } & \multicolumn{2}{c}{ Sum of weight of twins } \\
\hline MM & 0.3095 & $(\mathrm{n}=1,189)$ & 0.3186 & $(\mathrm{n}=1,185)$ & $0.2843 \quad(\mathrm{n}=1,179)$ \\
MF & 0.3945 & $(\mathrm{n}=287)$ & 0.3049 & $(\mathrm{n}=286)$ & $0.3358 \quad(\mathrm{n}=284)$ \\
FM & 0.3392 & $(\mathrm{n}=249)$ & 0.2105 & $(\mathrm{n}=248)$ & $0.2296 \quad(\mathrm{n}=244)$ \\
FF & 0.3072 & $(\mathrm{n}=1,214)$ & 0.3299 & $(\mathrm{n}=1,210)$ & $0.2887 \quad(\mathrm{n}=1,204)$ \\
\hline Total & 0.3361 & $(\mathrm{n}=2,939)$ & $0.3318 \quad(\mathrm{n}=2,929)$ & $0.3044 \quad(\mathrm{n}=2,911)$ \\
\hline
\end{tabular}

of twin pairs below the median was $45.2 \%(568 / 1,256)$ in $\mathrm{DZ}$ and $52.7 \%(1,153 /$ $2,186)$ in $\mathrm{MZ}$ twins. A higher figure in $\mathrm{MZ}$ than $\mathrm{DZ}$ twins was more evident at one year of age: $28.2 \%(298 / 1,058)$ in $\mathrm{DZ}$ and $63.4 \%(1,175 / 1,854)$ in $\mathrm{MZ}$ twins.

Table 7 shows interclass correlation coefficient between the weight at birth and that at one year of age for the first-born, the second-born and the sum of weight of twins according to sex compositions. The coefficients were all significant at the level of 0.1 percent, indicating that there was a close relationship between the weight at birth and that at one year of age for twin individuals and twin pairs.

Table 8 shows means of the sum of weight of twins at birth and at one year of age according to sex compositions. It also shows the increase of the sum of weight from birth to one year of age and growth rate, the latter was defined as the percentage increase divided by the sum of weight at birth. The increase was the 
Table 8. Sum of body weight of twins. Means at birth, at one year of age, increase and growth rate.

\begin{tabular}{cllll}
\hline $\begin{array}{c}\text { Sex } \\
\text { compositions }\end{array}$ & \multicolumn{1}{c}{ At birth } & \multicolumn{1}{c}{$\begin{array}{c}\text { At one year } \\
\text { of age }\end{array}$} & \multicolumn{1}{c}{ Increase } & Growth rate* \\
\hline MM & $5,015(\mathrm{n}=1,415)$ & $19,123(\mathrm{n}=1,179)$ & $14,114(\mathrm{n}=1,179)$ & $291(\mathrm{n}=1,179)$ \\
MF & $5,081(\mathrm{n}=338)$ & $18,706(\mathrm{n}=285)$ & $13,630(\mathrm{n}=284)$ & $276(\mathrm{n}=284)$ \\
FM & $5,177(\mathrm{n}=290)$ & $18,818(\mathrm{n}=244)$ & $13,649(\mathrm{n}=244)$ & $272(\mathrm{n}=244)$ \\
FF & $4,823(\mathrm{n}=1,399)$ & $18,078(\mathrm{n}=1,204)$ & $13,276(\mathrm{n}=1,204)$ & $285(\mathrm{n}=1,204)$ \\
\hline Total & $4,957(\mathrm{n}=3,442)$ & $18,625(\mathrm{n}=2,912)$ & $13,681(\mathrm{n}=2,911)$ & $286(\mathrm{n}=2,911)$ \\
\hline
\end{tabular}

* See text.

Table 9. Number of pairs according to growth rate, below or above the median (275).

\begin{tabular}{cccr}
\hline $\begin{array}{c}\text { Sex } \\
\text { compositions }\end{array}$ & $\begin{array}{c}\text { Growth rate less than } \\
\text { or equal to 275 }\end{array}$ & $\begin{array}{c}\text { Growth rate more } \\
\text { than 275 }\end{array}$ & Total \\
\hline MM & 538 & 641 & 1,179 \\
MF & 168 & 116 & 284 \\
FM & 145 & 99 & 244 \\
FF & 607 & 597 & 1,204 \\
\hline Total & 1,458 & 1,453 & 2,911 \\
Estimated number & & & \\
MZ & $832(44.9 \%)$ & $1,023 \quad(55.1 \%)$ & 1,855 \\
DZ & $626(59.3 \%)$ & $430 \quad(40.7 \%)$ & 1,056 \\
\hline Total & 1,458 & 1,453 & 2,911 \\
\hline
\end{tabular}

highest in MM pairs, followed by MF and FM pairs, and the lowest in FF pairs. Growth rates were higher in like-sexed than in unlike-sexed twins. The growth rate was classified into two groups, below or above the median $(=275)$ of total 2,911 pairs, and thenumber of $\mathrm{MZ}$ and $\mathrm{DZ}$ twins were estimated by Weinberg's method separately for two groups (Table 9). In this estimation the similar assumtion, as in Table 6, was again used. Relative frequency of $\mathrm{MZ}$ twin pairs above the median was higher $(55.1 \%, 1,023 / 1,855)$ than that of $\mathrm{DZ}$ twin pairs $(40.7 \%$, $430 / 1,056)$.

Interclass correlation coefficient between the growth rate and the sum of weight of twins at one year of age was $0.3402(n=2,914, p<0.001)$, while that between the growth rate and the sum of weight at birth was $-0.7631(n=2,914, p<0.001)$. In order to examine the relationship more in detail, the sum of weight at birth was classified into nine subgroups, and the growth rate was subjected to analysis of 
Table 10. Growth rate according to the sum of weight at birth.

\begin{tabular}{lccc}
\hline $\begin{array}{c}\text { Subgroups of the sum } \\
\text { of weight at birth }(g)\end{array}$ & Mean & Standard deviation & Number of pairs \\
\hline 3,500 or less & 450 & 80 & 134 \\
$3,500-$ & 369 & 64 & 244 \\
$4,000-$ & 323 & 50 & 443 \\
$4,500-$ & 287 & 42 & 725 \\
$5,000-$ & 259 & 40 & 662 \\
$5,500-$ & 235 & 35 & 447 \\
$6,000-$ & 218 & 34 & 193 \\
$6,500-$ & 199 & 35 & 49 \\
7,000 or more & 176 & 29 & 14 \\
\hline Total & 286 & 72 & 2,911 \\
\hline
\end{tabular}

Table of analysis of variance

\begin{tabular}{lccr}
\hline & Suin of squares & Degree of freedom & Mean square \\
\hline Between groups & $9,001,555.75$ & 8 & $1,125,194.47$ \\
Within groups & $6,126,426.44$ & 2,902 & $2,111.10$ \\
Total & $15,127,982.19$ & 2,910 & \\
\hline
\end{tabular}

$\mathrm{F}=533.00$.

variance. It was indicated, as seen in Table 10, that growth rate was gradually decreased as the sum of weight at birth was increased. Regression analysis resulted in the following formula, regression coefficient being highly significant.

$$
\mathrm{GR}=619.0-67.4 \times \mathrm{SUMB}
$$

(GR, growth rate; SUMB, sum of weight at birth $(\mathrm{kg})$ )

\section{DISCUSSIONS}

In twin individuals who were live-born and surviving at one year of age, the distribution of weight at one year of age revealed lower coefficient of variation, larger kurtosis and positively shifted skewness, if compared to that at birth (Table 2). This result suggests that the handicap usually accompanying twin individuals with less body weight at birth diminishes in the course of development up to one year of age.

As for intrapair difference at birth and age one year, increased intraclass correlation coefficient and decreased percent deviation were seen (Tables 4 and 5), 
indicating the weight becomes more similar to each other between the pair. It was also indicated that percent deviation within the pair was lower in like-sexed than in unlike-sexed twins, in particular at the age one year, where estimated frequency below the median of percent deviation was markedly higher in $\mathrm{MZ}(63.4 \%)$ than in DZ twins $(28.2 \%$ ) (Table 6), suggesting an effect of genotype on the gain of weight. Wilson (1979) has reported longitudinal study on the weight of twins, in which within-pair correlation at birth was $0.63,0.68$ and 0.64 for MZ, same-sexed $\mathrm{DZ}$ and opposite-sexed DZ twins, respectively. At one year of age, it was 0.88 , 0.55 and 0.37 , respectively. The present result is in accordance with that by Wilson (1979), who mentioned that $\mathrm{MZ}$ twins should become increasingly concordant with age, if initial differences in birth size were present to which some intrauterine conditions may be responsible.

As for the relative frequency above the median of growth rate, estimated figure was higher in $\mathrm{MZ}(55.1 \%)$ than in DZ twins $(40.7 \%)$ (Table 9), indicating that MZ twins are more capable in weight development than $\mathrm{DZ}$ twins, though birth weight was lower in $\mathrm{MZ}$ twins than $\mathrm{DZ}$ twins, as reported in the previous study (Asaka, Imaizumi and Inouye, 1980).

It was indicated that the lower the sum of weight of twins at birth, the higher the growth rate at one year of age (Table 10). Wilson (1979) reported that the weight deficit of twins at birth showed dramatic recovery in the first three months, then smaller subsequent reductions until it was fully offset by eight years. He also mentioned that the lightest twins (10th centile), who were the most sharply depressed in birth weight, nevertheless made the largest postnatal gain. The present result is in good agreement with his observations.

This study was supported in part by the Grant Aided by the Ministry of Health and Welfare of Japan for the Handicapped Children, 1979.

\section{REFERENCES}

Asaka, A., Imaizumi, Y. and Inouye, E. 1980. Analysis of multiple births in Japan. I. Weight at birth among 12,392 pairs of twins. Jpn. J. Human Genet. 25: 65-71.

Imaizumi, Y. and Inouye, E. 1979. Analysis of multiple birth rates in Japan. I. Secular trend, maternal age effect, and geographical variation in twinning rates. Acta Genet. Med. Gemellol. 28: $107-124$.

Imaizumi, Y., Asaka, A. and Inouye, E. 1980. Analysis of multiple birth rates in Japan. II. Secular trend, and effect of birth order, maternal age and gestational age in stillbirth rate of twins. Acta Genet. Med. Gemellol. (in press)

Wilson, R.S. 1979. Twin growth: Initial deficit, recovery, and trends in concordance from birth to nine years. Ann. Human Biol. 6: 205-220. 